\title{
Modeling of Fault Activation and Seismicity by Injection Directly into a Fault Zone associated with Hydraulic Fracturing of Shale-gas Reservoirs
}

\author{
Jonny Rutqvist*, Antonio P. Rinaldi, Frédéric Cappa, and George J. Moridis \\ Lawrence Berkeley National Laboratory, Earth Sciences Division, Berkeley, CA 94 720, USA \\ * Corresponding author. Tel.: +1-510-486-5432, fax.: +1-510-486-5432 \\ E-mail address: $\underline{\text { Jrutqvist@lb.gov (J. Rutqvist) }}$
}

\begin{abstract}
We conducted three-dimensional coupled fluid-flow and geomechanical modeling of fault activation and seismicity associated with hydraulic fracturing stimulation of a shale-gas reservoir. We simulated a case in which a horizontal injection well intersects a steeply dipping fault, with hydraulic fracturing channeled within the fault, during a 3-hour hydraulic fracturing stage. Consistent with field observations, the simulation results show that shale-gas hydraulic fracturing along faults does not likely induce seismic events that could be felt on the ground surface, but rather results in numerous small microseismic events, as well as aseismic deformations along with the fracture propagation. The calculated seismic moment magnitudes ranged from about -2.0 to 0.5 , except for one case assuming a very brittle fault with low residual shear strength, for which the magnitude was 2.3, an event that would likely go unnoticed or might be barely felt by humans at its epicenter. The calculated moment magnitudes showed a dependency on injection depth and fault dip. We attribute such dependency to variation in shear stress on the fault plane and associated variation in stress drop upon reactivation. Our simulations showed that at the end of the 3-hour injection, the rupture zone associated with tensile and shear failure extended to a maximum radius of about $200 \mathrm{~m}$ from the injection well. The results of this modeling study for steeply dipping faults at 1000 to $2500 \mathrm{~m}$ depth is in agreement with earlier studies and field observations showing that it is very unlikely that activation of a fault by shale-gas hydraulic fracturing at great depth (thousands of meters) could cause felt seismicity or create a new flow path (through fault rupture) that could reach shallow groundwater resources.
\end{abstract}


1

2

3

4

\section{Introduction}

The rapid increase in North American shale-gas energy production has been made possible through new technology development, including extended-reach horizontal drilling and multistage hydraulic-fracture stimulation. But these new technologies have also raised concerns related to a range of local environmental problems (Arthur et al. 2008; Zoback et al. 2010)). One concern, investigated in this study, is whether shale-gas hydraulic fracturing could activate faults and thereby cause seismicity, opening up flow paths for upward fluid leakage and possible contamination of shallow potable groundwater resources (Arthur et al. 2008; Zoback et al. 2010; Davies et al., 2013; Rutqvist et al., 2013).

A first modeling study to investigate the potential consequences of fault reactivation during shale-gas hydraulic fracturing operations was presented in Rutqvist et al. (2013). Consistent with field observations, the study showed that a hydraulic fracturing operation to stimulate a deep shale-gas reservoir could only give rise to limited fault rupture, along with the possibility of (unfelt) microseismicity. In another study, Flewelling et al. (2013) used injection data and elastic fracture volume and length relationships to bound fracture-height data from 12,000 hydrofracturing stimulations conducted across North America. The hydraulic fracturing data showed that all microseismic events occurred less than $600 \mathrm{~m}$ above well perforation, although most were very much closer, and the farthest were usually associated with faults. These studies indicated that shale-gas hydraulic fracturing at great 
1 depth (thousands of meters) could not create flow paths for leakage to reach shallow 2 groundwater resources.

4 Studies have also concluded that the likelihood of inducing felt seismicity during shale-gas

5 hydraulic fracturing operations, while not to be ruled out completely, is extremely small

6 (National Research Council, 2012; Davies et al., 2013). Indeed, after hundreds of thousands

7 of shale-gas fracturing stages conducted to date, only three examples of felt seismicity have

8 been documented (Davies et al., 2013). In Lancashire County, UK, two seismic events of

9 Richter scale magnitude $M_{L}=2.3$ and 1.5 were likely induced by direct injection into a

10 fault zone that had not been previously mapped (De Pater and Baisch, 2011). In another

11 case at the Eola Field of Garvin County, Oklahoma, in January 2011 (Holland, 2011), there

12 was a clear temporal correlation between the time of stimulation and the occurrence of 43

13 earthquakes that ranged in magnitude from $M_{D}=1.0$ to 2.8 ( $M_{D}$ is the duration magnitude).

14 Finally, the third case of felt seismicity occurred at Etsho and Kiwigan fields in Horn River,

15 Canada, where 19 events between $M_{L}=2$ and 3 occurred having a clear temporal 16 correlation with the shale-gas operation; the largest (and felt) event, occurring in May 2011,

17 had a magnitude of $M_{L}=3.8$ (BC Oil and Gas Commission, 2012; Davies et al. 2013). Each

18 of these three cases of felt seismicity have been associated with reactivation of faults.

20 The biggest modeling uncertainty in the previous fault-activation modeling by Rutqvist et

21 al. (2013) was a 2D simplification of the full 3D field settings. In 2D plane-strain

22 simulations, it is difficult to estimate a representative injection rate, and some assumptions

23 have to be made about the shape of the rupture area (e.g., circular with diameter equal to 
1 2D rupture length), which affects the calculated seismic magnitude. In this study we

2 conduct, for the first time, a full 3D model simulation of fault activation associated with

3 shale-gas fracturing. In such a 3D model simulation, the exact injection rate from the 3D

4 field is a direct model input, and the seismic magnitude can be evaluated directly from the

5 calculated rupture area and mean slip without the model uncertainties inherent in a 2D

6 simplification. In this new 3D modeling study, we simulate the case in which a horizontal

7 well intersects a subvertical fault, which then can be reactivated by injection directly into

8 the fault. In addition, we investigate some issues not addressed in the previous 2D modeling

9 in Rutqvist et al. (2013), including how the results correlate with fault and injection depth,

10 fault dip, and fault frictional properties. We conclude with a discussion relating our

11 modeling results to field observations and attempt to explain under which conditions a

12 shale-gas fracturing stimulation could induce a felt seismic event.

16 We adopted the modeling approach that was applied in the previous 2D modeling study in

17 Rutqvist et al. (2013). That is, we used the coupled multiphase fluid-flow and 18 geomechanical simulator TOUGH-FLAC (Rutqvist, 2011) to model water-injection and

19 fault responses, and we applied seismological theories to estimate the corresponding 20 seismic magnitude. The fault was modeled as a discrete feature using finite thickness

21 elements having anisotropic elasto-plastic properties. Shear failure was governed by a 22 Mohr-Coulomb constitutive model with strain-softening frictional strength properties, 23 consistent with a seismological slip-weakening fault model (Cappa and Rutqvist, 2011). 
1 This allowed us to model sudden (seismic) slip events and to estimate their seismic magnitude. The adopted modeling approach has also been extensively applied for modeling

3 fault activation associated with underground $\mathrm{CO}_{2}$ injection (e.g. Cappa and Rutqvist, 2012;

4 Mazzoldi et al., 2012; Rinaldi et al., 2014).

5

6 The model domain and the material properties are presented in Fig. 1 and Table 1, 7 respectively. We model a full 3D-geological system (x, y, z: $2 \mathrm{~km} \times 10 \mathrm{~km} \times 2 \mathrm{~km}$ ) generally

8 tuned towards conditions that could be encountered in the Marcellus shale-gas play in the

9 Northeastern U.S. This includes model input of in situ stress, fluid pressure, temperature,

10 material properties, and injection rates. In a base-case simulation, we adopt conditions

11 consistent with areas where the Marcellus shale is located at a depth of about $2000 \mathrm{~m}(6562$

$12 \mathrm{ft})$. The model is representative of the Marcellus shale-gas play with a $30 \mathrm{~m}$ thick gas-

13 bearing shale, bounded at the top and bottom by other low-permeability formations (such as

14 inorganic gray shale and limestone). This system is intersected by a steeply dipping fault,

15 which in the base case has a dip of $80^{\circ}$. We simulate a case in which the horizontal 16 injection well intersects the fault, and we directly inject the fluid volume related to a 3-hour 17 hydraulic fracturing stage directly into the fault.

19 We set the initial conditions assuming linear pore pressure and temperature gradients (9.81 $20 \mathrm{MPa} / \mathrm{km}$ and $25^{\circ} \mathrm{C} / \mathrm{km}$, respectively), with constant hydraulic boundary conditions (i.e., 21 open to fluid flow), except for the planes $\mathrm{x}=0$ and $\mathrm{y}=0$ where a no-flow condition is 22 applied (Fig. 1). Mechanical boundary conditions are null displacement at $\mathrm{x}=0$ and $\mathrm{y}=0$ 23 planes, and constant stress elsewhere. The initial stress field is selected to represent the 
1 conditions at the Marcellus shale play as detailed and justified in Rutqvist et al. (2013). We

2 first set the vertical stress gradient (maximum principal stress) to $26,487 \mathrm{~Pa} / \mathrm{m}$,

3 corresponding to an overburden density of about $2700 \mathrm{~kg} / \mathrm{m}^{3}$. We then consider the

4 minimum principal stress to be horizontal and oriented parallel to the horizontal well,

5 which would lead to vertical hydro-fractures perpendicular to the well, but which in this

6 case follow the weak planes of the fault. This does also correspond to a normal faulting

7 stress field, in which the minimum horizontal stress (and minimum principal stress) is

8 directed normal to the strike of the fault. We set the magnitude of the initial minimum

9 horizontal stress corresponding to a horizontal-over-vertical stress ratio of $R=\sigma_{\mathrm{h}} / \sigma_{\mathrm{V}}=0.6$.

10 There are uncertainties in the horizontal-over-vertical stress ratio and, as highlighted by

11 Rutqvist et al. (2013), this ratio has an impact on the magnitude of fault shear activation.

12 However, several sources (e.g. Cipolla et al., 2010) indicate a fracture closure stress of 13 about $0.7 \mathrm{psi} / \mathrm{ft}$ and this corresponds to a horizontal-over-vertical stress ratio of $R=\sigma_{\mathrm{h}} / \sigma_{\mathrm{V}}=$

14 0.6. In this study, we keep the horizontal-over-vertical stress ratio fixed at $R=\sigma_{\mathrm{h}} / \sigma_{\mathrm{V}}=0.6$,

15 but vary the depth of the system, which also means a variation in stress magnitude at the

16 depth of the injection. The magnitude of the intermediate stress, which in this case of a

17 normal faulting stress regime would be oriented parallel to the fault strike does not affect

18 the potential for shear failure along the fault.

20 Another important parameter in our analysis is the shear strength of the fault and how it 21 evolves along with the reactivation. Here, we use the strain-softening Mohr-Coulomb 22 model, in which the coefficient of friction and cohesion decreases with slip, i.e., once the 
1 peak shear strength is achieved and the fault slips, the cohesion drops to zero and the coefficient of friction drops to a residual value. In the numerical model, this is simulated by reducing the coefficient of friction and cohesion from peak to residual values over a plastic shear strain of $10^{-3}$ (Cappa and Rutqvist, 2011). In the base case, we use a coefficient of friction of $\mu=0.6$, with a residual value (after slip) equal to $\mu_{R}=0.4$, whereas the cohesion drops to zero from an initial value of $1 \mathrm{MPa}$. A larger difference between the peak and residual friction values represents a more brittle behavior that is expected to lead to a larger shear-stress drop and seismic event. The selection of the frictional coefficient parameters are also discussed and justified in Rutqvist et al. (2013), acknowledging that this is one possible set of reasonable values of the frictional coefficient. The fault shear strength and how it weakens with slip is defined by a set of parameters that are varied in this study

Other fault properties as well as properties of the shale listed in Table 1 are equivalent to those used and justified in Rutqvist et al. (2013). In this study, we assume that the fault is nearly impermeable (hydraulically indistinguishable from the host rock), though the permeability and porosity can increase as a result of fracturing and shear. We consider a nearly impermeable fault a realistic assumption in this case. As pointed out by Flewelling et al. (2013), hydrocarbons cannot accumulate where there are permeable faults serving as pathways for buoyant oil and gas to leak upward. A relevant example of an impermeable fault in shale is a fault zone in Opalinus Clay exposed at the Mont Terri Rock Laboratory, Switzerland (Croisé et al., 2004). This zone is several meters thick, consists of intensively fractured rocks, has an inferred shear offset of $5 \mathrm{~m}$, but is still hydraulically indistinguishable from the host rock, having an estimated permeability $k=2 \times 10^{-20} \mathrm{~m}^{2}$ 
1 (Croisé et al., 2004). Consistent with such a conceptual model, we considered $3.3 \mathrm{~m}$ thick

2 fault where fracturing can take place along weak planes such as healed fractures along the

3 fault plane, meaning that the tensile strength is low and taken as $1.7 \mathrm{MPa}$, based on the

4 extension of the Mohr-Coulomb failure envelope into tension. Such a low tensile strength is

5 reasonable, considering published shale strength data, including laboratory measurements

6 on bedding planes and tectonic shears in Opalinus Clay (Bock, 2009; Young et al., 2010),

7 and past laboratory experiments on Marcellus black-shale samples (Heard and Lin, 1986).

9 We consider porosity and permeability changes in the fault with tensile and shear rupture,

10 according to a conceptual model of fracturing and shear along a fault zone rather than

11 opening of a single hydraulic fracture. In this model, as soon as tensile or shear failure

12 propagates within the fault plane, the porosity increases with plastic tensile strain $\varepsilon_{t}^{p}$ and

13 plastic shear strain a $\varepsilon_{S}^{P}$ according to:

$$
\phi=\phi_{0}+\phi_{f}=\phi_{0}+\varepsilon_{t}^{p}+\varepsilon_{s}^{p} \times \tan \psi
$$

15 where $\psi$ is the shear dilation angle. The approach of changing porosity with rupture is 16 associated with the constitutive ubiquitous joint model, where plastic tensile and shear 17 strain can be extracted and used for superimposing porosity changes by the rupture. The 18 porosity increase due to the fracturing provides additional fluid storage that is important to 19 consider in the fluid-flow simulation and significantly affects the fracturing propagation. 
1 Similarly, the tensile and shear rupture also provides permeability that is superimposed on

2 the initial fault permeability. The adopted permeability-change model described in Rutqvist

3 et al. (2013), considers changes in equivalent fractured rock permeability along the fault as

4 a function of plastic strain normal to the fault plane:

$$
k=k_{0}+k_{f}=k_{0}+A\left(\varepsilon_{n}-\varepsilon_{n}^{t}\right)^{3}
$$

where $k_{0}$ is the initial fault permeability, $A$ is a constant, and $\varepsilon_{n}^{t}$ is a threshold strain related required crack opening displacement for onset of permeability changes. Here, we used $\varepsilon_{n}^{t}=$

$8 \quad 1 \times 10^{-4}$ and $A=1 \times 10^{-5}$, meaning that permeability would increase to about $1 \times 10^{-14}$ to $1 \times 10^{-}$

$9{ }^{11} \mathrm{~m}^{2}$ for a plastic strain normal to the fault on the order of $1 \times 10^{-3}$ to $1 \times 10^{-2}$. This is a very 10 substantial permeability change from an initial permeability of $1 \times 10^{-19} \mathrm{~m}^{2}$, one that 11 provides rapid pressure diffusion along the fractured elements with the fracture 12 propagation.

14 We simulated a typical hydraulic fracturing stimulation stage with injection at a rate of 200 $15 \mathrm{~kg} / \mathrm{s}(75 \mathrm{bbl} / \mathrm{min})$ for 3 hours. According to Fig. 1, the horizontal section of the well is 16 explicitly represented and connected to elements at the fault to simulate injection focused at 17 a packed-off section of the well. We assumed that a fracture had already been initiated and 18 extended within the fault to about $10 \mathrm{~m}$ from the well. Such fracture initiation would in the 19 field be the result of an initial pressurization to formation breakdown pressure (e.g. 20 Mayerhofer et al., 2011). We assume this initial fracture because the model is not refined 21 enough around the well to properly simulate fracture initiation and formation breakdown. 
1 In the field, the injection is typically shut down for a few minutes before beginning the main stimulation stage (e.g., Mayerhofer et al., 2011), which in our simulation is assumed

3 to be 3 hours long.

5 During the stimulation, the fracture is extended within the fault plane, as illustrated in Fig.

6 1. We then evaluate magnitude and frequency of microseismic events as well as the total

7 extent of the rupture zone. The seismic moment $M_{0}$, and the moment magnitude $M_{w}$ are

8 evaluated for newly ruptured patches on the fault (related to the propagation of the

9 fracturing front). According to Kanamori and Anderson (1975) and Kanamori and Brodsky

10 (2001), we have $M_{0}=A \mu d$ and $M_{w}=\left(\log _{10} M_{0} / 1.5\right)-6.1$, where A $\left[\mathrm{m}^{2}\right]$ is the area of the

11 rupture, $\mu[\mathrm{Pa}]$ is shear modulus of the rock, and $d[\mathrm{~m}]$ is the average slip on the rupture. In

12 the modeling, a total of $2160 \mathrm{~m}^{3}$ (571,611 gallons) of water were injected during the 3-hour

13 simulated injection.

14

15 3. Modeling results

16

17 In the following subsections, we first present the results of the base-case simulation, 18 considering injection at $2000 \mathrm{~m}$ depth into a fault dipping 80 degrees, and having a 19 coefficient of friction $\mu=0.6$ that upon reactivation drops to a residual value $\mu_{R}=0.4$. We 20 then present parameter studies to evaluate the sensitivity of the results to changes in 21 injection depth (1000 to $2500 \mathrm{~m})$, fault dip $\left(75^{\circ}\right.$ to $\left.90^{\circ}\right)$, and fault friction coefficients $(0.2$ 22 to 0.8 ). In each case, we evaluate the results in terms of number and maximum magnitude 23 of microseismic events, and the total vertical rupture length along the fault. 


\subsection{Base-case simulation results}

3 Fig. 2 presents the simulation results for the base case: Fig. 2a shows the pressure

4 evolution, whereas Fig. $2 b$ shows the magnitude of fault slip (the along-dip offset

5 displacement between the hanging wall and foot wall of the fault) and moment magnitudes

6 of seismic events. Note that the initial stress normal to the fault at the depth of the injection

7 is about 32.5 MPa. Fig. 2a shows how the injection pressure increases to reach a peak value

8 of about $43 \mathrm{MPa}$ and then slowly decreases along with the failure propagation. Fig. $2 \mathrm{~b}$

9 shows that shear displacement is initiated after a few minutes of injection-when the

10 pressure exceeds the stress normal to the fault - and then slips gradually along with the

11 propagation of the failure zone. The biggest microseismic events occur during the first few

12 minutes of injection, and then microseismicity continues during the 3-hour injection at

13 reduced magnitudes and frequency_but also continues for at least 10 minutes after

14 terminating the injection (after 180 minutes). The simulated magnitude of the microseismic

15 events generally ranges between $M_{w}=-2$ and 0 . Fig. $2 \mathrm{c}$ to e show that at the end of the

16 hour injection, the failure zone has extended to a radius of almost $200 \mathrm{~m}$ from the well

17 upwards and laterally, while only about $100 \mathrm{~m}$ downwards. This can be explained by the

18 vertical gradient in stress that makes it easier to propagate a fracture upwards. Moreover, at

19 the end of the 3-hour injection, the fault slip is almost $5 \mathrm{~cm}$ at the center of the failure zone

20 (near the injection well). The simulation in Fig. 2 captures results typical for hydraulic

21 fracturing, including (1) small pressure fluctuations, especially during the first 20 minutes

22 when failure and shear slip occur relatively close to the injection well, (2) a gradual

23 reduction in the pressure required to propagate the fracture for a given injection rate, and 
1 finally, (3) a typical pressure fall-off after terminating the injection. After terminating the

2 injection and shutting in the well (at $180 \mathrm{~min}$ ), the well pressure declines to below the stress

3 normal to the fault plane (32.5 MPa), in a shut-in pressure behavior that could be used in

4 the field to estimate the minimum principal stress magnitude.

6 Overall, the result from the base-case simulation shows that maximum moment magnitude

7 is less than 0.5, and the total rupture is less than $200 \mathrm{~m}$ up from the injection. Field

8 observations show that during typical stimulation operations in the North American shale-

9 gas basins (Marcellus, Barnett, Eagle Ford, Woodford, Haynesville, Horn River), the

10 maximum moment magnitude in a stimulation stage ranges between $M_{W}-2.5$ to (in rare

11 cases) up to $M_{W}=1.0$, with the high-end values usually associated with faults (Warpinski,

12 2009; Warpinski et al., 2012). The simulated microseismic events are within this range,

13 with the lower limit probably affected by the minimum size of element patches in the fault

14 (10 by $10 \mathrm{~m}$ ) that can rupture in one instance. This means that in our modeling, we model

15 the relatively larger microseismic events occurring from shear slip along the fault plane,

16 whereas in the field, there are numerous smaller-magnitude events perhaps occurring as a

17 result of slip in small-scale fractures in the host rock surrounding the fault, and these are

18 not resolved in our modeling.

\subsection{Sensitivity to injection depth}

21 In their review of thousands of hydraulic fracturing treatments in North American shale 22 basins, Warpinski et al. (2012) noticed an increased microseismic magnitude and frequency

23 with depth. In Fig. 3, we present an analysis in which we varied the injection depth from 
$1 \quad 1000$ to $2500 \mathrm{~m} \mathrm{(3281} \mathrm{to} 8202 \mathrm{ft}$ ). The trend is clear and shows an increasing maximum

2 magnitude and frequency with depth (Fig. 3f). Note that, from Fig. 3a, b, and d, although

3 the total shear slip magnitude increases with depth, the extent of the rupture zone is

4 equivalent, i.e., always about $200 \mathrm{~m}$ up from the injection point. We attribute the increased

5 total shear-slip magnitude with depth to a higher shear stress on the fault when going

6 deeper. A higher shear results in a greater shear-stress drop upon reactivation, and the shear

7 slip is proportional to the shear-stress drop for a given fracture extent and shear modulus.

8 The higher shear stress can also explain the increased moment magnitude of seismic events

9 with depth. Overall, such depth dependency is consistent with field observations in

10 Warpinski et al. (2012).

\subsection{Sensitivity to fault dip}

13 Fig. 4 presents the results for a different fault dip, between 75 and $90^{\circ}$. The results in Fig.

14 4f show that the maximum magnitude and frequency increase for decreasing dip angle. The

15 results in Fig. 4 also show a significant difference in tensile and shear behavior. The plastic

16 tensile strain in Figure 4a (signifying tensile failure) propagates farthest for a vertical fault

$17\left(90^{\circ}\right)$, whereas the plastic shear strain in Fig. $4 \mathrm{~b}$ (signifying shear slip) propagates farthest

18 in the case of inclined faults (e.g., $75^{\circ}$ ). The tensile failure propagates the longest for a

19 vertical fault because the initial stress normal to the fault is the lowest in this case (32.4

$20 \mathrm{MPa}$ ), slightly lower than for the inclined faults (e.g., $33.2 \mathrm{MPa}$ for the $75^{\circ}$ fault). The very

21 small events $\left(\mathrm{M}_{\mathrm{W}}=-3\right.$ to -2$)$ for a vertical fracture resulted from minute shear displacement

22 (about 1 micron) when new surface patches failed in tension. Shear failure propagates 
1 longer for inclined faults, as well as both shear slip and microseismic magnitudes increase,

2 because the initial shear stress is much higher (e.g., $5.3 \mathrm{MPa}$ for the $75^{\circ}$ fault compared to 0

3 for the $90^{\circ}$ fault). However, even for an inclined fault, when the shear stress is the highest,

4 the event magnitudes are less than about $\mathrm{M}_{\mathrm{W}}=0.7$.

5

\subsection{Sensitivity to slip-weakening model parameters}

The coefficient of friction and its evolution during failure may affect the amount of stress drop and thereby the amount of slip and seismic magnitude. In the base case, coefficient of frictions $\mu=0.6$ and $\mu_{R}=0.4$ were used. A coefficient of friction of 0.6 is commonly applied in fault-stability analyses and has been identified as a lower limit value for the most common rocks (Zoback, 2007). However, clay-rich fault rock and fractures in shale could have a much lower coefficient of friction, especially under wet conditions (Zoback, 2007; Samuelson et al., 2012). Another data source are the investigations of Opalinus Clay at the Mont Terri underground research laboratory, which indicates a coefficient of friction of about 0.4 along bedding planes (Bock, 2009; Young et al., 2010). One additional complicating factor is that the coefficient of friction is rate dependent and is also dependent of the clay content (Kohli and Zoback, 2013). Kohli and Zoback (2013) determined coefficient of friction on fractures in Barnett, Haynesville, and Eagleford shale samples to be in the range of 0.4 to 0.8 , for high to low clay content. Moreover, unstable slip behavior was noted for shale with lower clay content, i.e. when the initial coefficient of friction was in the range of 0.6 to 0.8 . 
3 Because of the uncertainty in the selection of coefficient of friction, we conducted 4 sensitivity studies involving both peak and residual friction values. Moreover, we varied the 5 rate of frictional strength drop with plastic shear strain. In the base case it was assumed that 6 the coefficient of friction drops from $\mu=0.6$ to $\mu_{R}=0.4$ over a plastic shear strain of $10^{-3}$. 7 As discussed in Cappa and Rutqvist (2011), shear strength drop with plastic shear strain can 8 be related to a fault slip weakening model, commonly applied in earthquake seismology, 9 and the evolution of shear stress with slip (Kanamori and Bodsky, 2004). A plastic shear 10 strain of $10^{-3}$ across the fault width of 3.33 m corresponds to a fault shear slip of $3.33 \times 10^{-3}$ $11 \mathrm{~m}(3.33 \mathrm{~mm})$. This would correspond to the critical slip distance, $\mathrm{Dc}=3.33 \times 10^{-3} \mathrm{~m}$ in a slip 12 weakening model, meaning that the coefficient of friction reduces to its residual value 13 (dynamic friction) over a slip displacement of $3.33 \mathrm{~mm}$ (Aochi et al., 2014). In the base 14 case, the maximum shear strain after the 3-hour injection is on the order of $10^{-2}$ and a shear 15 maximum slip is up to $5 \mathrm{~cm}$ (Fig. 2). However, the incremental plastic shear strain and slip 16 during each event is much smaller, with slip magnitudes on the order of $1 \times 10^{-5}$ to $5 \times 10^{-4} \mathrm{~m}$

17 for event magnitudes ranging from about $M_{w}=-2$ to 0 . This means that the full frictional 18 strength drop from $\mu=0.6$ to $\mu_{R}=0.4$ will not occur and this may in turn affect the shear 19 stress drop during an event. Although a critical slip distance of $3.3 \mathrm{~mm}$ is within the range 20 of laboratory measurements on rough fractures (Ohnaka, 2013), the value could vary by 21 orders of magnitude depending on scale (Ohnaka 2003) and might be strongly 22 heterogonous in a fault plane (Aochi et al., 2014). Moreover, recent laboratory data on 23 shale by Kohli and Zoback (2013) indicated values on the order of tens of microns, i.e. very 
1 small values. Again, the values could vary by orders of magnitude when going from core

2 sample scale to field scale (Ohnaka, 2003), leading to considerable uncertainty in this 3 parameter.

5 Acknowledging the uncertainties we investigate the sensitivity to changes in peak and 6 residual friction coefficient and the critical slip distance. Figure $5 f$ shows that there is a 7 trend of fewer but higher magnitude microseismic events if reducing the critical slip 8 distance to as low as $10^{-5} \mathrm{~m}$. With such a low critical slip distance, the full shear strength 9 drop corresponding to a drop in the coefficient of friction from $\mu=0.6$ to $\mu_{R}=0.4$ would 10 occur as soon as shear failure occurs. Moreover, quite surprisingly, the analysis showed the 11 rather small influence of peak and residual friction coefficient, for variations in the initial 12 coefficient of friction between $\mu=0.5$ to 0.8 and for residual coefficient of friction between $13 \mu_{R}=0.3$ to 0.6 . It is only when the residual coefficient of friction is reduced to 0.2 that we 14 see more significant change in calculated moment magnitudes and rupture length, including 15 a maximum moment magnitude of $M_{W}=2.3$ (Figure 6f). These relatively larger events can 16 be observed in Fig. 5d as more significant slip displacements occur at 70, 100, and 160 17 minutes. The $M_{W}=2.3$ event is of similar magnitude as those felt at the aforementioned 18 U.K. and Oklahoma incidents, though such small magnitude events may likely go 19 unnoticed. Note that if the residual coefficient of friction is $\mu_{R}=0.2$, then the shear stress 20 on the fault from the tectonic stress field (about 3.6 MPa) is higher than the residual shear 21 strength of the fault (about 2.5 MPa). This means that once fault activation is initiated, 22 shear strength within the rupture area will drop to below the prevailing shear stress, and 23 because of this weakening, the shear slip can self-propagate outside the zone of 
1 pressurization. This is the reason why in the case of $\mu_{R}=0.2$, the shear rupture is somewhat

2 larger. Nevertheless, this result indicates that the only way to produce a microseismic event

3 above $M_{W}=2$ in the current model setting is for the residual fault shear strength to be less

4 than the prevailing shear stress.

\section{Discussion}

7

Overall, the results of this $3 \mathrm{D}$ simulation study are in agreement with the findings in the

9 previous 2D study in Rutqvist et al. (2013), in terms of potential extent of the rupture and

10 magnitude of seismic events. The moment magnitudes calculated in this study ranged from

11 about $M_{W}=-2.5$ to 0.5 , except for the special case of very low residual coefficient of

12 friction of 0.2 , when a magnitude $M_{W}=2.3$ event was calculated. Over the duration of the

13 3-hour injection, repeated events and aseismic slip were shown to amount to up to $0.06 \mathrm{~m}$,

14 with the total radius of rupture extending up to $200 \mathrm{~m}$.

15

16 Consistent with field monitoring, the modeling shows that when faults are present, 17 somewhat larger seismic events are possible - compared to those associated with regular 18 hydraulic fracturing seismic events-because larger surface areas are available for 19 rupturing (Fisher and Warpinski, 2011: Warpinski et al., 2012). Indeed, regular hydraulic

20 fracturing seismic events average around $M_{W}=-2.5$, whereas higher than usual events up to 21 about $M_{w}=0.5$ are usually associated with fracturing along faults (Warpinski et al., 2012).

22 Moreover, the modeling results of repeated small microseismic events and aseismic slip 23 and fracture opening is consistent with field observations - that the energy emitted from 
1 microseismic events represents only a small fraction of the energy input or the energy to open the fracture (or fracture network) (Warpinski et al., 2012). Natural fractures present in

3 shale (Gale et al., 2014) may also open aseismically by increased fluid pressure and

4 associated reduction of effective stress (Rutqvist, 2014). In this context, weakly cemented

5 fractures being common in shales (Gale et al, 2014) could have a permeability that is

6 extremely stress dependent. Also consistent with our modeling, field observations of

7 fracturing along faults have shown that microseismic events can travel several hundred

8 meters upwards (Fisher and Warpinski, 2012; Flewelling et al., 2013; Yang and Zoback, 9 2014).

11 Our analysis showed that the frequency and magnitude of the microseismic events are 12 dependent on the initial shear stress on the fault plane, while the total rupture length is 13 limited by the volume of water injected. In the case of injection directly into the fault plane, 14 the shear activation (shear failure) occurs simultaneously with the hydraulic fracturing 15 (tensile failure), and these events takes place starting near the well and propagate away 16 from the well bore in repeated microseismic events. At greater depth and for inclined faults 17 that are more optimally oriented for higher shear stress, these microseismic events are of 18 slightly higher magnitude. This depth dependency is also consistent with field observations 19 at North American shale gas basins (Warpinski et al., 2012). An explanation from the 20 modeling is that upon reactivation, shear stress is relieved, and this shear-stress drop is 21 greater in the case of a higher initial shear stress, which in turn can results in larger slip for 22 a given rupture area. 
1 The total rupture length obtained in this study (about $200 \mathrm{~m}$ radius), will depend on the total injection volume and leak-off from the main hydraulic fracturing into surrounding

3 rock, as well as the initial gas saturation. In this case the conceptual model is a $30 \mathrm{~m}$ thick

4 gas bearing formation surrounded by gray shale and limestone layers that does not contain

5 gas, and in this analysis we simplified the system to be fully water saturated. If considering

6 some gas saturation in the gas bearing formation (e.g. 50\%), the hydraulic fracturing

7 process could be affected by the fact that gas is much more compressible than water

8 therefore delaying the pressurization for a given injection rate (e.g. Rinaldi and Rutqvist,

9 2014). However, as shown in Kim et al. (2014), hydraulic fracturing of shale gas reservoirs

10 may be affected by complex two-phase flow processes, including vertical gravity

11 segregation within the created fractures. To investigate these effects Kim et al., (2014)

12 conducted a hydraulic fracturing simulation of a shale-gas reservoir for the extreme cases

13 of water saturated and gas saturated rock, and achieved similar radial extent of the

14 stimulated fracture. Thus, we would not expect any major extension of the calculated

15 rupture zone if considering some initial gas saturation in $30 \mathrm{~m}$ thick gas bearing formation.

16 Nevertheless, the study in Kim et al., (2014) shows that the created fracture volume may

17 not be equal the injected volume due to two-phase flow effects and fluid leak-off to the

18 surrounding rock. Here, we injected $2160 \mathrm{~m}^{3}$ (571,611 gallons) of water over the 3-hour

19 injection, which can be considered a typical average injection volume per fracturing stage

20 (e.g., compared with data shown in Mayerhofer et al. (2011) and BC Oil and Gas

21 Commission (2012)). If injection were to continue or were at a higher rate, the rupture

22 would propagate slightly longer. However, this also means that the total length of the 
1 rupture zone can be controlled by limiting the total injection volume and guided by seismic

2 monitoring.

4 One important question is, under what conditions could it be possible to induce felt seismic

5 events? We would emphasize that only three such cases have been documented among

6 hundreds of thousands of hydraulic fracturing treatments, meaning that these are very rare

7 events, and hence it might be difficult to produce such events even in a numerical model.

8 Our analysis for the conditions considered in this study indicates that the only way to

9 produce events on the order of magnitude $M_{W}=2$ to 3 , is a very brittle fault with a residual

10 coefficient of friction lower than the prevailing shear stress on the fault (see results for a

11 residual coefficient $\mu_{R}=0.2$ in Fig. 5). In this case, sufficient new surface area can be

12 ruptured in one instance to produce a seismic event on the order of $M_{W}=2$ to 3 . Moreover,

13 consistent with field observations at the three known cases of felt events, these simulated

14 events occurred hours into the hydraulic fracturing stage, i.e., after 70, 100, and 160

15 minutes, in Fig. 5d. Each simulated event in Fig. 5d resulted in up to $1 \mathrm{~cm}$ fault slip, and the

16 total slip is greater than $6 \mathrm{~cm}$, which would certainly put some strain on the horizontal well.

17 Deformations of the horizontal wells were also observed at the incidents at Lancashire

18 County, U.K. and Horn River, Canada. However, some of the shale-gas-fracturing-related

19 events reported in the literature, e.g., the events at the Eola Field, Oklahoma, occurred

20 many hours after shut-in of the injection and farther away from the injection wells. This

21 may indicate channeling of injection fluid that, after some time, then enters a critically

22 stressed fault that then can be reactivated. Such a scenario is more in line with the

23 conceptual model in previous 2D modeling in Rutqvist et al. (2013), where we considered a 
1 hydraulic fracture propagating to intersect a fault, not injection directly into the fault. In

2 that study, such a fault could be reactivated many hours after continuous injection to

3 produce larger than usual microseismic events (e.g., magnitude 2). That is, if that fault had

4 some permeability, were near critically stressed, and had brittle slip properties with a low

5 residual strength. Thus, it could be that if fluid pressure migrates out of the shale layer it

6 might encounter more brittle, faulted rock types that could be a source of larger than usual 7 events.

8

9

10

11 We have conducted 3D model simulations of fault activation during a shale-gas hydraulic

12 fracturing operation that eliminates some important model uncertainties associated with

13 previous $2 \mathrm{D}$ modeling studies. We simulated a case tuned toward the conditions at the

14 Marcellus shale simulation, a hydraulic fracturing stage of $2000 \mathrm{~m}$, but with direct injection

15 into a steeply dipping fault. Thus, the entire water volume from one hydraulic fracturing

16 stage was injected to propagate a fracture along the fault. The results of the simulations are

17 consistent with field observations regarding the possible microseismic magnitude and

18 rupture length, indicating the occurrence of small (unfelt) microseismic events and fault

19 ruptures that could propagate upwards a few hundred meters from the injection interval.

20 The following main results were achieved in this modeling study:

21 - During the stimulation injection, the shear activation (shear failure) occurred

22 simultaneously with the hydraulic fracturing (tensile failure), starting near the well and

23 propagating away from the well in repeated microseismic events. 
21 Though our results in terms of seismic magnitudes are in agreement with field observations 22

- The moment magnitudes ranged from about $M_{W}=-2.5$ to 0.5 , except for the special case of a very brittle fault with a residual shear strength below the prevailing shear stress, when a magnitude $M_{W}=2.3$ event was calculated.

- The microseismic magnitude increased with depth and for inclined faults that are more optimally oriented for higher shear stress, indicating the dependency of shear-stress drop on the seismic magnitude.

- Over the course of the 3-hour injection, repeated events and aseismic slip amounted to up to $0.06 \mathrm{~m}$, with the total radius of the shear rupture extending up to $200 \mathrm{~m}$.

Overall, this 3D modeling study in agreement with previous findings showing that it is very unlikely that activation of a fault by shale-gas hydraulic fracturing at great depth (thousands of meters) could cause felt seismicity or create a new flow path (through fault rupture) that could reach shallow groundwater resources.

The analysis indicates that the very rare observations of felt seismicity associated with shale-gas fracturing (three documented out of several hundred-thousand fracturing stages) might have been caused by locally very unfavorable conditions, wherein fluid-pressure changes could reach a large section of a fault that was close to critically stressed for shear and having very brittle slip weakening properties in which the residual strength was lower than the prevailing shear stress.

2 at various U.S. shale-gas plays exposed to various stress regimes, our analysis was for the 
1 case of steeply dipping faults under a normal-faulting stress regime at 1000 to $2500 \mathrm{~m}$

2 depth. It might be different when operating a lot deeper such as could be the case in future

3 shale gas production in China. In such case, the stress field will be much higher, the shale

4 even tighter and potentially more brittle, and therefore potentially leading to larger

5 magnitude events.

6

7 Nevertheless, adequate site characterization for identifying and avoiding faults should be a

8 priority in any shale gas development. Moreover, continuous monitoring of induced

9 seismicity from the start of the injection can be used to detect any runaway fracturing along

10 faults. That is, to detect fracturing that propagates far above and below the gas-bearing

11 shale layer, indicating potential reactivation of a fault.

\section{Acknowledgments}

14 We thank the U.S. Environmental Protection Agency (EPA), Office of Research and

15 Development, for supporting this study under an Interagency Agreement (DW-89-

16 92378101) with the US Department of Energy at the Lawrence Berkeley National

17 Laboratory. The views in this article are those of the authors and do not necessarily reflect

18 the views or policies of the U.S. EPA. Mention of commercial software does not constitute

19 endorsement by EPA or LBNL.

20

\section{References}

22 Aochi H., Poisson B., Toussaint R., Rachez X., Schmittbuhl J., 2014. Self-induced 23 seismicity due to fluid circulation along faults. Gephys J Int, 196, 1544-1563. 
Arthur, J.D., Bohm B., Layne M., 2008. Hydraulic fracturing considerations for natural gas wells of the Marcellus shale. Presented at the Ground Water Protection Council 2008 Annual Forum, Cincinati, Ohio, USA, 21-24, Sep.

BC Oil and Gas Commission, 2012. Investigation of Observed Seismicity in the Horn River Basin. 〈http://www.bcogc.ca/publications/reports.aspx>

Bock HR. 2009. A experiment: updated review of the rock mechanics properties of the Opalinus Clay of the Mont Terri URL based on laboratory and field testing. Mont Terri Project, Technical Report 2008-04.

Cappa F., and Rutqvist J., 2011. Impact of $\mathrm{CO}_{2}$ geological sequestration on the nucleation of earthquakes. Geophys Res Lett, 38, L17313, doi:10.1029/2011GL048487.

Cappa, F., Rutqvist, J., 2012. Seismic rupture and ground accelerations induced by $\mathrm{CO}_{2}$ injection in the shallow crust. Geophysical Journal International, 190, 1784-1789.

Cipolla, C. L., Lolon, E.P., Erdle, J.C., Rubin, B., 2010. Reservoir modeling in shale-gas reservoirs. Society of Petroleum Engineers (SPE) Reservoir Evaluation \& Engineering. August 2010, SPE 125530.

Croisé, J., Schlickenrieder, L., Marschall, P., Boisson, J.Y., Vogel, P., Yamamoto, S., 2004. Hydrogeological investigations in a low permeability claystone formation: the Mont Terri Rock Laboratory. Physics and Chemistry of the Earth 29: 3-15.

Davies R., Foulger G., Bindley A., Styles P., 2013. Induced seismicity and hydraulic fracturing for the recovery of hydrocarbons. Marine and Petroleum Geology 45, 171-185.

De Pater, C.J., Baisch, S., 2011. Geomechanical study of Bowland shale seismicity. Synthesis Report, November 2011. Cuadrilla Resources Ltd, UK.

Ferrill, D.A., McGinnis, R.N., Morris, A.P., Smart, K.J., Sickmann, Z.T., Bentz, M., Lehrmann, D., Evans M.A.2014. Control of mechanical stratigraphy on bed-restricted jointing and normal faulting: Eagle Ford Formation, south-central Texas. AAPG Bulletin, v. 98 , no. 11 , p. $2165-2216$.

Fisher, K., Warpinski, N., 2011. Hydraulic Fracture-Height Growth: Real Data. Paper was prepared for presentation at the SPE Annual Technical Conference and Exhibition held in Denver, Colorado, USA, 30 October-2 November 2011. Society of Petroleum Engineers, SPE 145949.

Flewelling S.A., Tymchak M.P., Warpinski N. 2013. Hydraulic fracture height limits and fault interactions in tight oil and gas formations. Geophysical Research Letter, VOL. 40, 3602-3606. 
Gale, J. F. W., Laubach, S. E., Olson, J. E., Eichhubl, P., and Fall, A., 2014, Natural fractures in shale: a review and new observations. AAPG Bulletin, v. 98, no. 11, p. 21652216.

Holland, A., 2011. Examination of possibly induced seismicity from hydraulic fracturing in the Eola Field, Garvin County, Oklahoma. Oklahoma Geological Survey Open-File Report OF1-2011.

Kanamori, H., Anderson, D.L., 1975. Theoretical basis of some empirical relations in seismology, Bull. Seism. Soc. Am., 65, 1073-1095.

Kanamori, H., Brodsky, E.E., 2001. The physics of earthquakes. Physics Today (June 2001), 34-40.

Kim J., Um E.S., Moridis G.J., 2014. Fracture propagation, fluid flow, and geomechanics of water-based hydraulic fracturing in shale gas systems and electromagnetic geophysical monitoring of fluid migration. Paper prepared for presentation at the SPE Hydraulic Fracturing Technology Conference held in The Woodlands, Texas, USA, 4-6 February 2014. Society of Petroleum Engineeers, SPE 168578. Kohli, A.H., Zoback, M.D. 2013. Frictional properties of shale reservoir rocks, J. Geophys. Res. Solid Earth. 118, 1-17.

Mazzoldi, A., Rinaldi, A.P., Borgia, A., Rutqvist, J., 2012. Induced seismicity within geologic carbon sequestration projects: Maximum earthquake magnitude and leakage potential. International Journal of Greenhouse Gas Control, 10, 434-442.

Mayerhofer, M.J., Stegent, N.A. Barth J.O. and Ryan K.M. 2011. Integrating fracture diagnostics and engineering data in the Marcellus Shale. presentation at the SPE Annual Technical Conference and Exhibition held in Denver, Colorado, USA, 30 October-2 November 2011. SPE 145463.

National Research Council, 2012. Induced seismicity potential in energy technologies, National Academies Press, Washington D.C., pp. 300.

Ohnaka M., 2003. A constitutive scaling law and a unified comprehension for frictional slip failure, shear fracture of intact rock, and earthquake rupture. J Geophys Res, 108(B2), 2080 .

Rinaldi A.P., Rutqvist J., and Cappa F. 2014. Geomechanical effects on CO2 leakage through fault zones during large-scale underground injection. International Journal of Greenhouse Gas Control. 20, 117-131.

Rinaldi A.P., Rutqvist J., Sonnenthal E., L., and Cladouhos T.T. 2014. Coupled THM modeling of hydroshearing stimulation in tight fractured volcanic rock. Transport in Porous Media (Published online April 2014). DOI 10.1007/s11242-014-0296-5. 
Rutqvist, J., 2011. Status of the TOUGH-FLAC simulator and recent applications related to coupled fluid flow and crustal deformations. Computers \& Geosciences, 37, 739-750.

Rutqvist J. Fractured rock stress-permeability relationships from in situ data and effects of temperature and chemical-mechanical couplings. Geofluids (Published online, 2014). doi: 10.1111/gfl.12089.

Rutqvist, J., Birkholzer, J.T., Cappa, F., Tsang, C.-F., 2007. Estimating maximum sustainable injection pressure during geological sequestration of $\mathrm{CO} 2$ using coupled fluid flow and geomechanical fault-slip analysis. Energy Conv. Man., 47:1798-1807.

Rutqvist J., Rinaldi, A.P., Cappa, F., and Moridis G.J. 2013. Modeling of fault reactivation and induced seismicity during hydraulic fracturing of shale-gas reservoirs. Journal of Petroleum Science and Technology, 107, 31-44 (2013).

Samuelson, J., Spiers, C.J., 2012. Fault friction and slip stability not affected by Co2 storage: Evidence from short-term laboratory experiments on North Sea reservoir sandstones and caprocks. Int. J. Greenhouse Gas Control (in press) dx.doi.org/10.1016/j.ijggc.2012.09.018.

Warpinski N.R. 2009. Microseismic Monitoring: Inside and Out. Journal of Petroleum Technology, November 2009. Society of Petroleum Engineers, SPE 118537.

Warpinski, N.R., M.J. Mayerhofer, K. Agarwal, and J. Du. 2012. Hydraulic fracture geomechanics and microseismic source mechanisms. Society of Petroleum Engineers J. 17:766-780.

Yang, Y., Zoback M.D., 2014. The role of preexisting fractures and faults during multistage hydraulic fracturing in the Bakken Formation. Interpretation. 2, SG25-SG39.

Yong S., Kaiser P.K., Loew S., 2010. Influence of tectonic shears on tunnel-induced fracturing. International Journal of Rock Mechanics \& Mining Sciences, 47, 894-907.

Zoback, M.D. 2007. Reservoir Geomechanics. Cambridge University Press, Cambridge, UK.

Zoback, M., Kitasei, S., Copithorne, B., 2010. Addressing the Environmental Risks from Shale Gas Development Briefing Paper1. Natural Gas and Sustainable Energy Initiative, World watch Institute, Washington, July2010 (http://www.worldwatch.org). 
Table 1. Rock characteristics considered in the base-case simulation

\begin{tabular}{lcc}
\hline Parameters & Shale & Fault \\
\hline Young's modulus, E $(\mathrm{GPa})$ & 30 & 30 \\
Poisson's ratio, $\nu(-)$ & 0.2 & 0.2 \\
Rock density, $\rho_{s}\left(\mathrm{~kg} / \mathrm{m}^{3}\right)$ & 2700 & 2700 \\
Biot's coefficient, $\alpha(-)$ & 1 & 1 \\
Matrix friction angle $\varphi\left({ }^{\circ}\right)$ & - & 75 \\
Matrix cohesion $(\mathrm{MPa})$ & - & 6 \\
Matrix tensile strength $(\mathrm{MPa})$ & - & 1.6 \\
Joint peak friction angle, $\varphi\left(^{\circ}\right)$ & - & 31 \\
Joint residual friction angle $\varphi\left(^{\circ}\right)$ & - & 22 \\
Joint cohesion $(\mathrm{MPa})$ & - & 3 \\
Joint residual cohesion & & 0 \\
Joint tensile strength $(\mathrm{MPa})$ & - & 1.6 \\
Joint dilation angle, $\psi\left({ }^{\circ}\right)$ & - & 10 \\
Permeability, $k\left(\mathrm{~m}^{2}\right)$ & $10^{-19}$ & $10^{-19}$
\end{tabular}




\section{Figure captions}

Figure 1. (Left) 2D-view of the boundary conditions used in the (Right) 3D model geometry for simulating injection and hydraulic fracturing within an $80^{\circ}$ dipping fault.

Figure 2. Results of a base-case simulation for a 3-hour long hydraulic fracturing stage considering injection at $2000 \mathrm{~m}$ depth into a fault dipping 80 degrees, and having a peak coefficient of friction of 0.6 and a residual friction of 0.4: (a) Downhole well pressure and (b) fault slip and events moment magnitude as function of time, and (c to e) pore pressure, plastic shear strain (signifying shear slip), and plastic tensile strength (signifying tensile failure) at the end of the 3-hour injection.

Figure 3. Sensitivity of simulation results to changes in injection depth: Vertical extent of (a) plastic tensile strain (signifying tensile failure) and (b) plastic shear strain (signifying shear slip), and time evolution of (c) well pressure and (d) slip magnitude, and (e) magnitude distribution for each value of injection depth and (f) frequency and maximum magnitude as a function of the injection depth.

Figure 4. Sensitivity of simulation results to changes in fault dip: Vertical extent of (a) plastic tensile strain (signifying tensile failure) and (b) plastic shear strain (signifying shear slip), and time evolution of (c) well pressure and (d) slip magnitude, and (e) magnitude distribution for each dip angle and (f) frequency and maximum magnitude as a function of fault dip angle.

Figure 5. Sensitivity of simulation results to changes in the critical slip distance (or equivalent plastic shear strain threshold) for shear strength drop : Vertical extent of (a) plastic tensile strain (signifying tensile failure) and (b) plastic shear strain (signifying shear slip), and time evolution of (c) well pressure and (d) slip magnitude, and (e) magnitude distribution for each value of the plastic shear strain threshold and (f) frequency and maximum magnitude as a function of plastic shear strain threshold.

Figure 6. Sensitivity of simulation results to changes in residual coefficient of friction: Vertical extent of (a) plastic tensile strain (signifying tensile failure) and (b) plastic shear strain (signifying shear slip), and time evolution of (c) well pressure and (d) slip magnitude, and (e) magnitude distribution for each value of the residual friction and (f) frequency and maximum magnitude as a function of residual coefficient of friction. 

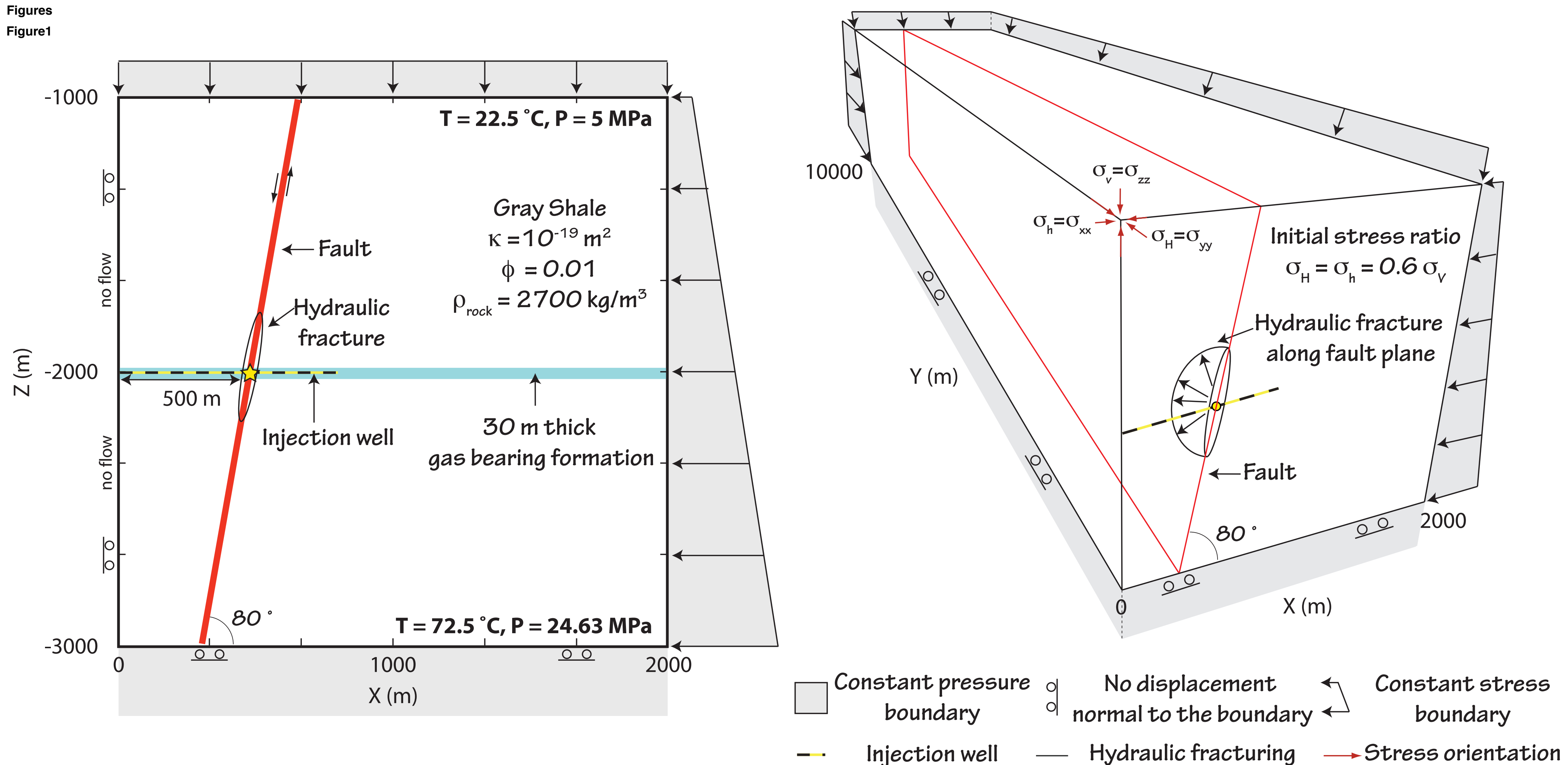
Figure3
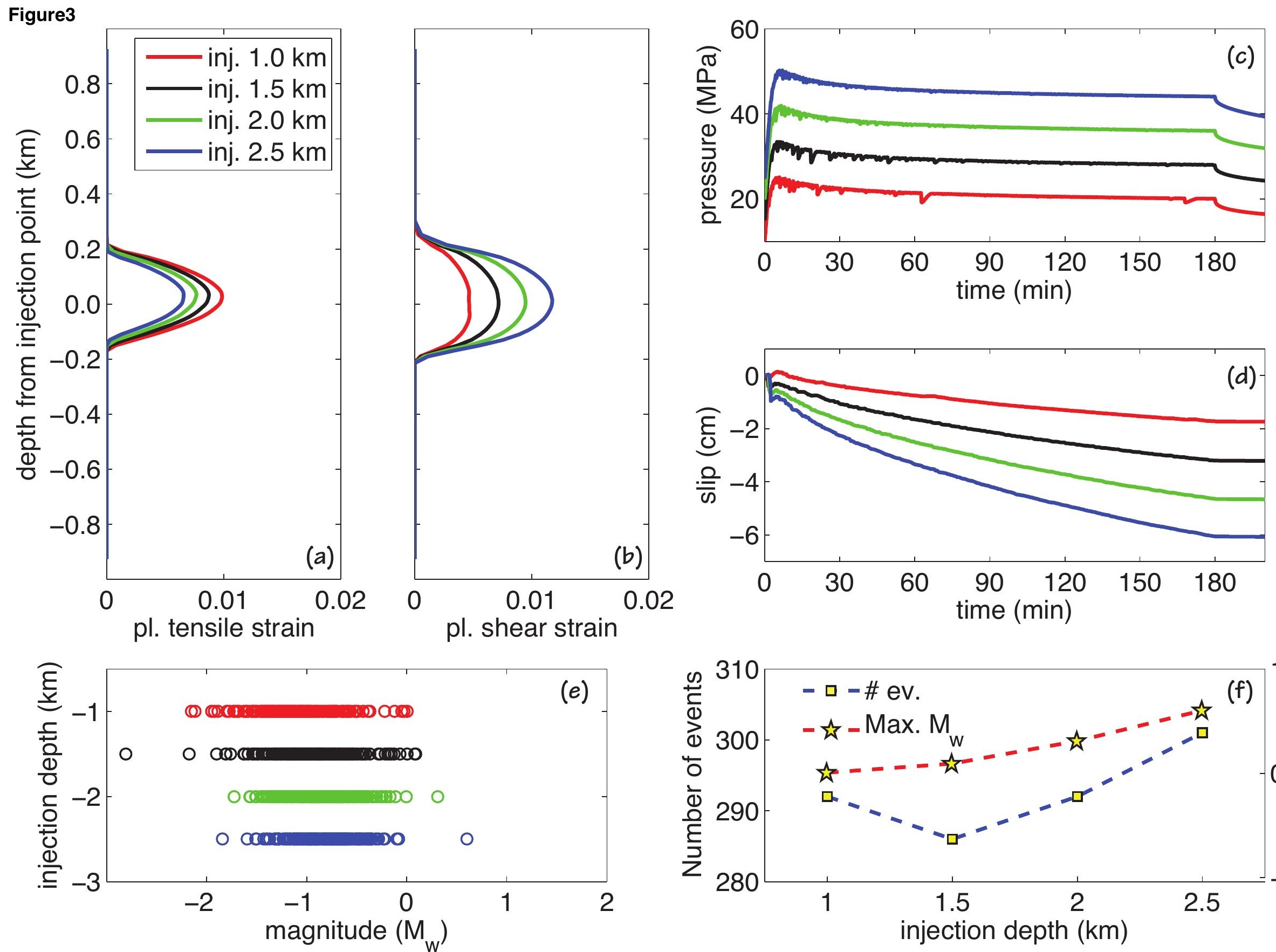
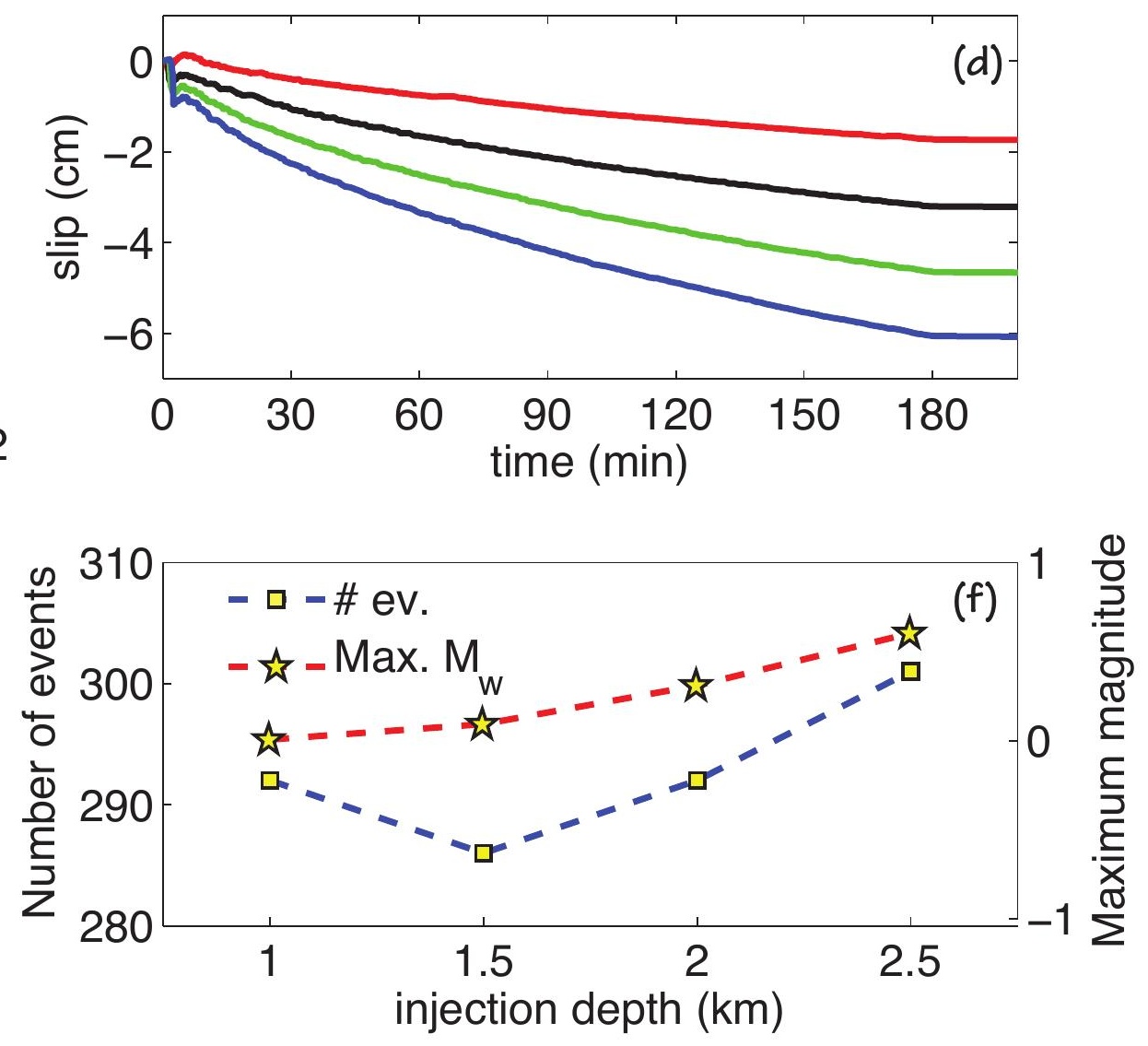
Figure4

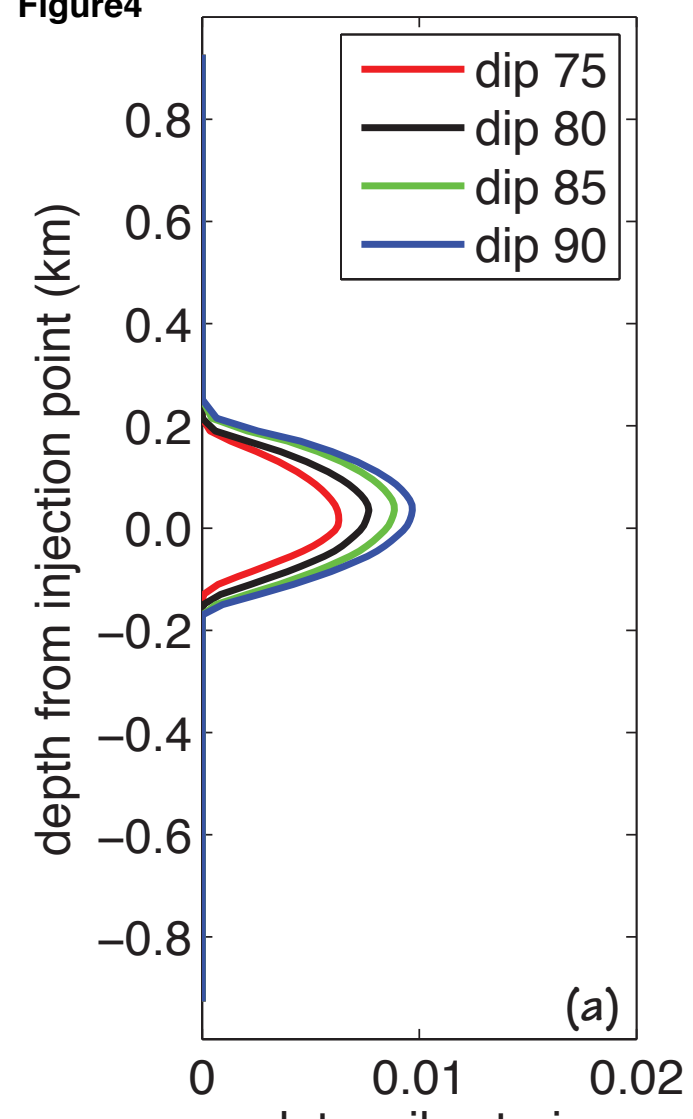

pl. tensile strain

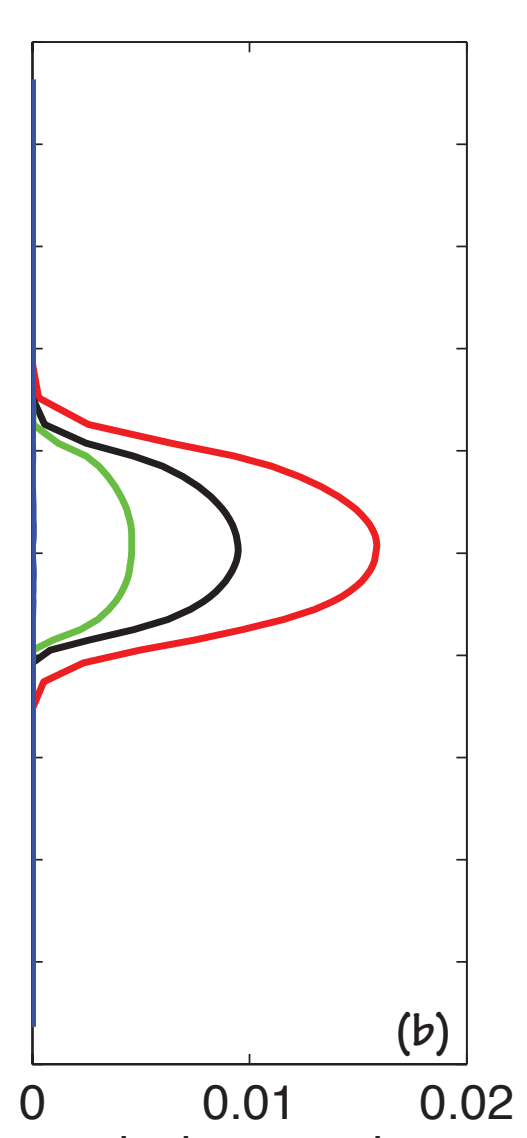

pl. shear strain
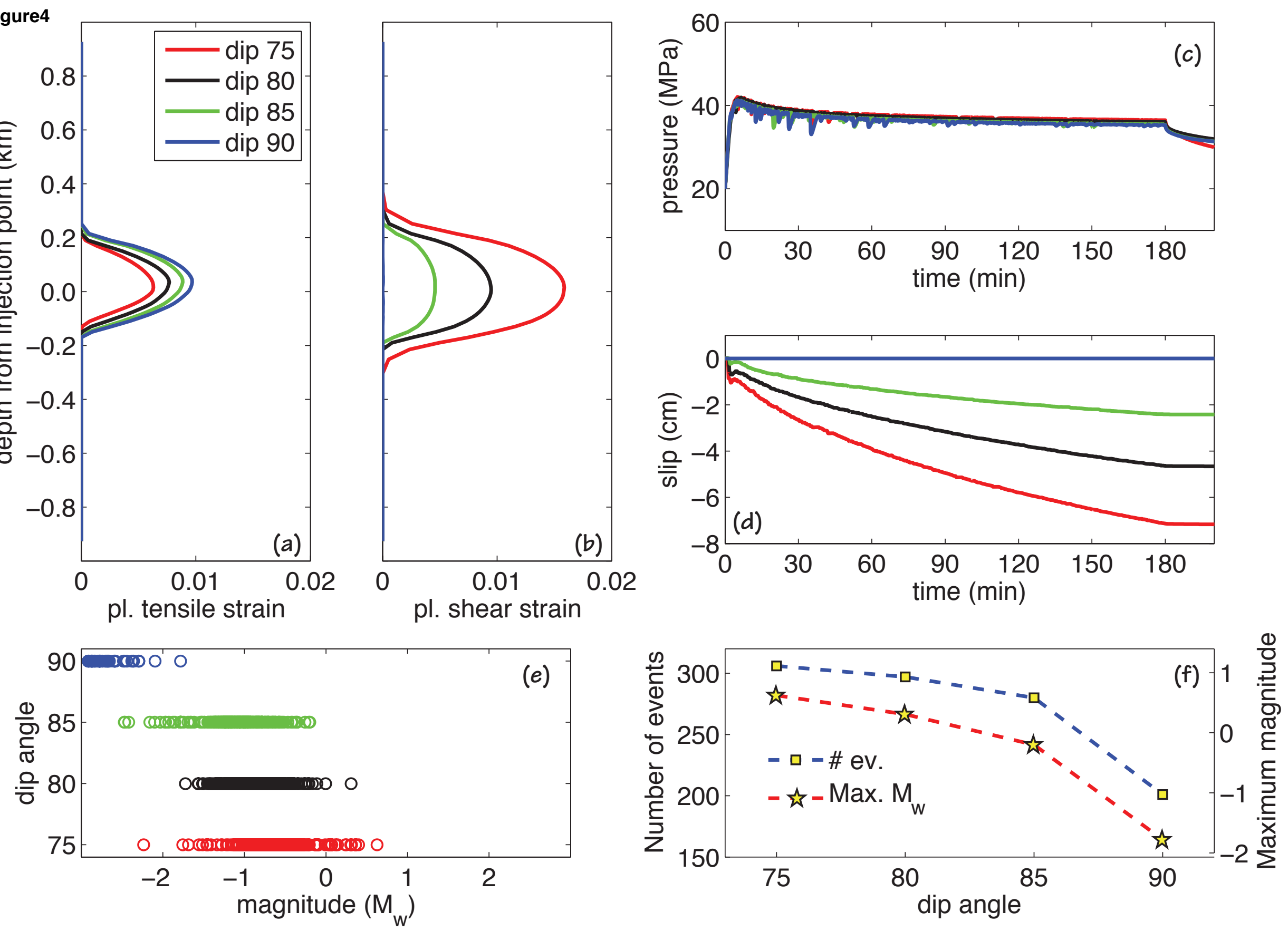
